Article

\title{
Excluded from the Good Life? An Ethical Approach to Conceptions of Active Ageing
}

\author{
Larissa Pfaller ${ }^{1, *}$ and Mark Schweda ${ }^{2}$ \\ ${ }^{1}$ Institute of Sociology, Friedrich-Alexander University Erlangen-Nürnberg, 91054 Erlangen, Germany; \\ E-Mail: larissa.pfaller@fau.de \\ 2 Division of Ethics in Medicine, Department of Health Services Research, Carl von Ossietzky University Oldenburg, 26129 \\ Oldenburg, Germany; E-Mail: mark.schweda@uni-oldenburg.de \\ * Corresponding author
}

Submitted: 15 December 2018 | Accepted: 17 April 2019 | Published: 29 July 2019

\begin{abstract}
Contesting previous deficit-oriented models of ageing by focusing on the resources and potential of older people, concepts of 'successful', 'productive', and 'active ageing' permeate social policy discourses and agendas in ageing societies. They not only represent descriptive categories capturing the changing realities of later phases of life, but also involve positive visions and prescriptive claims regarding old age. However, the evaluative and normative content of these visions and claims is hardly ever explicitly acknowledged, let alone theoretically discussed and justified. Therefore, such conceptions of 'ageing well' have been criticised for promoting biased policies that privilege or simply impose particular practices and lifestyles. This appears problematic as it can obstruct or even effectively foreclose equal chances of leading a good life at old age. Against this backdrop, our contribution aims to discuss current conceptions of active ageing from an ethical point of view. Starting from an analysis of policy discourses and their critique, we first examine the moral implications of prominent conceptions of active ageing, focusing on evaluative and normative premises. By employing philosophical approaches, we analyse these premises in light of a eudemonistic ethics of good life at old age and detect fixations, shortcomings, and blind spots. Finally, we discuss consequences for ethically informed active ageing research and policies, highlighting the interrelations between one-sided ideals of ageing well and social discrimination and exclusion.
\end{abstract}

\section{Keywords}

active ageing; discourse; ethics; gerontology; good life; philosophy

\section{Issue}

This article is part of the issue "Old-Age Exclusion", edited by Wouter De Tavernier (KU Leuven, Belgium) and Marja Aartsen (OsloMet-Oslo Metropolitan University, Norway).

(C) 2019 by the authors; licensee Cogitatio (Lisbon, Portugal). This article is licensed under a Creative Commons Attribution 4.0 International License (CC BY).

\section{Introduction}

On its website, the International Council on Active Aging ([ICAA], 2018) commits to "the conviction that people can significantly improve the quality of their later years by staying active and fully engaged in life". The network, with more than 10.000 members in 37 countries, has dedicated itself to the idea of active ageing and its public promotion and economic exploitation. Its mission statement declares that the ICAA aims "to dispel society's myths about aging" and "to empower aging Baby Boomers and older adults to improve their quality of life and maintain their dignity" (ICAA, 2018).

The example highlights central aspects of contemporary active ageing discourses. It first illustrates how the idea of active ageing permeates media, policy, and industry reasoning and communication in ageing societies. Furthermore, it shows that 'active ageing' not only represents a descriptive category capturing the changing realities of later phases of life. As the quotes make clear, 
the concept challenges previous deficit-oriented models of ageing-"society's myths about aging" - and emphasises the resources and potential of older people. In doing so, positive visions and prescriptive claims regarding old age come into play, in this case, "quality of life" and "dignity".

However, the evaluative and normative content of such visions and claims is hardly ever acknowledged, let alone discussed and justified. They often simply seem to mirror the value system of the respective era, political agenda, or sociocultural context. Consequently, conceptions of active ageing have been criticised for promoting biased policies that privilege or impose particular practices and lifestyles (Timonen, 2016). In the context of modern pluralistic societies and liberal democracies, this appears problematic as it can obstruct or even foreclose equal chances of leading a good life at old age (e.g., for people with disabilities, chronic diseases, cognitive impairments, socio-cultural minorities, or socioeconomically underprivileged groups).

Against this backdrop, our contribution aims to discuss conceptions of active ageing from an ethical point of view. We first provide an overview of contemporary policy discourses on active ageing. On this basis, we identify and examine the moral implications of prominent conceptions of active ageing and its critique, focusing on evaluative and normative premises regarding activity and lifestyle. In the next step, we employ philosophical approaches in order to analyse these premises in light of a eudemonistic ethics of good life at old age and detect fixations, shortcomings, and blind spots. Finally, we discuss consequences for ethically informed active ageing research and policies, highlighting the interrelations between one-sided ideals of ageing well and social discrimination and exclusion from the good life. As we will argue, introducing an ethical perspective can help strengthen the argumentative foundations of the debate by clarifying underlying values and norms.

\section{Active Ageing and Its Discontents}

Scientific discussions on active ageing started to boom at the beginning of the 2000s in response to the 2002 World Health Organization (WHO) strategy. The publication figures reached double-digits in 2004. While there were only 176 publications from 2000 to 2009, the number tripled to 481 from 2010 to $2018 .{ }^{1}$ By now, the concept of active ageing has come into common usage not only in policy (Boudiny, 2013, p. 1078), but also in gerontology and social science (van Dyk, 2014, p. 94).

There are various views on the concept's origins. Boudiny (2013, p. 1077) traces it back to the activity theory of ageing in the 1960s. Contesting the contemporary disengagement theory, this approach assumed that staying active and keeping up social participation were preconditions of sustained health, quality of life, and social utility in old age. Moulaert and Biggs (2013) focus on the emergence of active ageing in international policy during the G7 and G8 Summits in the late 1990s but also acknowledge an "enduring presence" (Moulaert \& Biggs, 2013, p. 26) in gerontology since the 1920s (see also Katz, 1996). Walker (2002) describes active ageing as a relatively new concept in politics, but sees its origins in the gerontological discourse on successful ageing (Rowe \& Kahn, 1987), highlighting the idea of ageing successfully by maintaining values and activity patterns of middle adulthood (Havighurst, 1961; Havighurst \& Albrecht, 1953).

There is also little agreement on the exact meaning of active ageing (Boudiny, 2013, p. 1078). The term does not stand for a discrete concept but is often intertwined with ideas of healthy, productive, or successful ageing (Boudiny, 2013, p. 1078; Katz, 2013; Walker, 2002 , p. 122). In comparison to these related interpretations of ageing well, the discussion around active ageing is rather young and its popularity is fuelled by political rather than gerontological discourses (Walker, 2002, p. 122). Boudiny distinguishes three kinds of definitions: "unidimensional approaches" (Boudiny, 2013, p. 1079), "multidimensional approaches" (Boudiny, 2013, p. 1082), and approaches "transcending the behavioural level" (Boudiny, 2013, p. 1084). Unidimensional approaches focus on only one aspect, usually physical activity or employment. By contrast, multidimensional approaches also consider other dimensions of life such as social and leisure activities. Approaches transcending the behavioural level further widen the scope by including factors like autonomy, social support, economic circumstances, and especially health and independence.

The emergence of active ageing in international policy was widely welcomed by contemporary gerontology (Moulaert \& Biggs, 2013, pp. 26-29). Thus, Walker (2002, p. 137) applauded the "beauty of this strategy [that is] good for everyone". However, active ageing and related concepts have also provoked criticism from critical gerontology and sociology of ageing. Besides objections regarding theoretical and empirical shortcomings, the most prominent line of critique focuses on moral and political concerns revolving around the problem of exclusion at the intersection of age and social inequality (Katz \& Calasanti, 2015, p. 29). According to the critics, there are severe structural differences in the distribution of resources for successful and active ageing due to dimensions of social inequality (especially gender, race, ethnicity, class, and sexuality). The effects of this social inequality unfold over the entire course of a person's life and culminate in old age. Moreover, with advancing age, older people are also increasingly exposed to ageism and age discrimination. Thus, already existing discrimination is further aggravated (Katz \& Calasanti, 2015, p. 296).

Against this backdrop, Ranzijn criticises active ageing as "another way to oppress marginalized and disadvantaged elders" (Ranzijn, 2010, p. 716) as the concept devalues their life experiences. He advocates alter-

\footnotetext{
${ }^{1}$ International Bibliography of the Social Sciences (IBSS), search: keyword in title or abstract.
} 
native conceptions of ageing well that are more sensitive to the cultural diversity of ageing and promote social inclusion (Ranzijn, 2010, p. 716). In addition, Boudiny (2013, p. 1081) also addresses the levels of physical and socio-economic diversity. From this perspective, unidimensional approaches are often criticised for adhering to a reduced understanding of activity and neglecting non-economic contributions to society. Thus, they exclude those who no longer partake in paid work, who contribute to society in other ways, but also those who suffer from physical limitations as well as the old-old in the fourth age (Boudiny, 2013, pp. 1080-1081). Multidimensional approaches are also conceptualised without including the old-old as this group is associated with non-active leisure patterns and therefore stigmatised. Approaches transcending the behavioural level still exclude the oldest-old and have a tendency to hypostasise health. As a result, they are often not clearly distinguished from healthy ageing concepts which focus on maintaining and improving the health of older people (Boudiny, 2013, pp. 1084-1087).

\section{Guiding Concepts: Productive Activity and Individual Lifestyle}

Using a genealogical approach, Moulaert and Biggs (2013) reconstruct the trajectory of active ageing in international politics and address the various players (e.g., G7/G8, OECD, WHO, United Nations) and the shifts in the definition. According to them, two prominent narratives of contemporary ageing are engaged in the discourse, one focusing on productivity and one on health and well-being (Moulaert \& Biggs, 2013, p. 29). These narratives are described as "economic instrumentalism" and "holistic self-development" (Moulaert \& Biggs, 2013, p. 29) and mirror corresponding lines of conflict and their development over time. Accordingly, two evaluative and normative guiding concepts can be identified: one is being "able to lead a productive life" and the other being "free to make personal choices" (Moulaert \& Biggs, 2013, p. 28).

A background paper entitled "Active Aging: A Shift in the Paradigm" and introduced in the 1997 G8 Summit by the US Department of Health and Human Services can be traced as the first text explicitly using the term 'active ageing' at an international policy level. From here, the term found its way into the communiqué of the Summit (Moulaert \& Biggs, 2013, p. 27). Since this was the initiation for the idea of active ageing in international policy, a quote from this paper can serve as a starting point to illustrate how notions of active ageing involve evaluative and normative assumptions regarding activity as productive activity and lifestyle as a matter of individual choice:

We discussed the idea of 'active aging' - the desire and ability of many older people to continue work or other socially productive activities well into their later years and agreed that old stereotypes of seniors as dependent should be abandoned. We considered new evidence suggesting that disability rates among seniors have declined in some countries while recognizing the wide variation in the health of older people. We discussed how our nations can promote active aging of our older citizens with due regard to their individual choices and circumstances, including removing disincentives to labor force participation and lowering barriers to flexible and part-time employment that exist in some countries. In addition, we discussed the transition from work to retirement, life-long learning and ways to encourage volunteerism and to support family care giving. $(G 8,1997$, para. 7$)$

The quote introduces active ageing in the context of the state's idea of a modern working biography. Consequently, the concept becomes related to "productive/work-based solutions" (Moulaert \& Biggs, 2013 , p. 25). Within this frame of economic instrumentalism, activity is defined through work and other "socially productive" activities. Thus, active ageing is ultimately equated with productive ageing. In this perception, retirement in ageing societies is considered a "waste of human resources" (G7, 1996, p. 7). However, it usually remains unclear why exactly productivity should be a good measure for activity or-vice versa-what exactly should be wrong with such a perspective.

In the following years, the discourse of active ageing was complemented by a "more holistic vision of participation" (Moulaert \& Biggs, 2013, p. 28). The WHO and the United Nations adopted a comparatively sophisticated line of thought in connection to the concept of activity that focused on self-development. Also according to Moulaert and Biggs (2013, p. 28), this led to a more balanced and differentiated definition of active ageing in the WHO's 2002 Policy Framework:

Active ageing is the process of optimizing opportunities for health, participation and security in order to enhance quality of life as people age. Active ageing applies to both individuals and population groups. It allows people to realize their potential for physical, social, and mental well being throughout the life course and to participate in society according to their needs, desires and capacities, while providing them with adequate protection, security and care when they require assistance. The word 'active' refers to continuing participation in social, economic, cultural, spiritual and civic affairs, not just the ability to be physically active or to participate in the labour force. (WHO, 2002, p. 12)

Although these more holistic interpretations circulate in international policy, the active ageing discourse still shows a strong inclination towards economic productivity (Boudiny, 2013; Moulaert \& Biggs, 2013; van Dyk, 2014). Research on active ageing tends to focus on labour-market participation. In addition, national govern- 
ments also often emphasise economic aspects in their active-ageing policies (Boudiny, 2013, p. 1079). As a result, pragmatic considerations quickly dominate the concrete implementation of holistic concepts; and holistic approaches are only accepted to the extent that they do not question the idea of productivity (Moulaert \& Biggs, 2013, pp. 29-30). Thus, when presenting his seven principles of active ageing, Walker (2002, p. 124) dedicated the first principle to a definition of activity that should "consist of all meaningful pursuits which contribute to the well-being of the individual concerned, his or her family, the local community, or society at large". However, although he emphasises that activity should not be reduced to employment, the definition highlights a positive outcome or usefulness of actions and also immediately adds that the importance of work should not be questioned. Against this backdrop, the idea of a holistic version of active ageing is often dismissed as "empty rhetoric" (Boudiny, 2013).

Indeed, conceptions promoting holistic selfdevelopment also raise concerns about their evaluative and normative foundations. In particular, they are challenged as manifestations of a shift towards neoliberalism, a socio-economic paradigm focusing on individual choice, economic competition, and free markets that systematically neglects the relevance of personal ties and political communities in social life (Boa \& Gans-Morse, 2009). From this perspective, 'active ageing' appears to be little more than a strategic catchphrase for the promotion of activating social policies and a fundamental re-negotiation of old age in times of social welfare cuts (van Dyk, 2014). Thus, while critical gerontology contests economic visions of activity for reducing old age to an exploitable resource, holistic approaches are also interpreted in light of an increasing responsibilization of old age (Cardona, 2008). Moulaert and Biggs, for example, argue that "international discourses on 'active ageing' may be considered as the meeting point of 'productive ageing' centred on economic priority and personal responsibilization analysed as a normalizing discourse for neoliberal subjects" (Moulaert \& Biggs, 2013, p. 38). In this interpretation, the holistic appeal to identity and personal development is actually only aimed to claim and control subjects in an even more pervasive and comprehensive way by holding them personally responsible for the way they grow old. Indeed, Walker interprets the WHO definition as suggesting a "general lifestyle strategy for the preservation of physical and mental health as people age, rather than just trying to make them work longer" (Walker, 2002, p. 124). In this way, older or, more generally, ageing people are not only addressed in terms of their labour force. Instead, all areas of their everyday life are comprised and reconsidered under the paradigm of activity and personal lifestyle choice. According to critics, however, the assumption that individual lifestyle is ultimately decisive for ageing well ignores the influence of social inequalities and systematic disadvantages (Holstein \& Minkler, 2003, p. 787; Katz, 2013). In ad- dition, the whole suggestion of an all-encompassing, i.e., both individual and social benefit of active ageing connecting the utilisation of the productive potential of older people with their better civic participation and thus improved quality of life (Walker, 2002, p. 137) has provoked critique (Stückler, 2016, p. 29). In this context, framing active ageing as a "win-win-situation" (van Dyk, 2014, p. 94) with benefits for both individuals and society is debunked as a purely ideological move. According to critical gerontology, the emphasis on personal responsibility actually functions as a mere alibi for dismantling the welfare state and shifting risks and costs to the single individual. As a consequence, the attribution of responsibility is not accompanied by more agency (Emirbayer \& Mische, 1998) and empowerment, but only by the burden of negative consequences.

\section{Introducing Ethical Perspectives on the Good Life to the Active Ageing Debate}

The active-ageing discourse is aimed at a positive vision of later life. Critical gerontology criticises the program as part of a neoliberal ideology and its biased notions of activity and lifestyle. Although both perspectives involve evaluative ideals and normative expectations regarding ageing and old age, these are hardly ever spelt out or discussed. In the following, we introduce an ethical perspective to take a closer look at these evaluative and normative implications of active ageing and its critique. To this purpose, we follow a eudemonistic approach to ethics focusing on conditions of a good life. This perspective has the advantage of acknowledging subjective ideas of and preferences for ageing expressed in terms of happiness and fulfilment while at the same time also comprising more objective aspects of accomplishment and human flourishing (Russell, 2010). We illustrate the approach's potential for the analysis of concepts of active ageing and the theoretical foundation of their discussion. In light of ethical considerations, the moral underpinnings regarding productive activity and self-determined individual lifestyle come to the fore, facilitating a more articulate critique of economic instrumentalism and holistic self-development.

From the eudemonistic perspective of an ethics of the good life, the most fundamental question regarding active ageing has to address an aspect that is hardly ever tackled in the debate: the central value ascribed to activity. What exactly is so good about being active in the first place? Why should activity as such be constitutive of a good life in general and a good life at old age in particular? After all, in light of the philosophical tradition, this emphasis on activity is far from self-evident. Major strands of classical and medieval philosophy, as well as spiritual thought, considered a life dedicated to intellectual insight, perception, or meditation as superior to any form of active life. Thus, Plato and Aristotle praised the theoretical life as divine because of its sublime sophistication and self-sufficiency (Cooper, 1987). And for promi- 
nent lines of Christian theology, a life of contemplation and mystic immersion rose above everyday hustle and bustle and brought the believer closer to god (Butler, 2001). According to Buddhist thought, meditation elevates the spirit from the material world and frees it from the illusions and restlessness of practical life. Many modern spiritual teachings consider a life of mindfulness as a pathway to higher levels of awareness, authenticity, and self-fulfilment (Bodhi, 2011).

Interestingly, pertinent considerations frequently draw connections to ageing and old age and thus also provide important viewpoints for the debate on active ageing. In the idea of wisdom, the association of superior insight and old age had already been commonplace in ancient thought (Robinson, 1990). Building on this tradition, Plato taught that philosophy benefits from growing older since ageing liberates the mind from bodily drives, sensual affects and inclinations, as well as practical interests, thus opening it for true intellectual comprehension (McKee \& Barber, 2001). The role of the philosopher typically included withdrawal from active public life and duties, a process that often came along with old age (McKee \& Barber, 2001). In modern ageing research, similar ideas were incorporated in the disengagement theory of ageing and related gerontological approaches. Disengagement theory held that it is natural and appropriate for the ageing person to withdraw from relationships and professional obligations, look back onto her past life and contemplate finiteness and approaching death (Cumming \& Henry, 1961). The accompanying decrease of social interaction was frequently associated with a release from social norms and thus with a vision of "late freedom" (Rosenmayr, 1987). Of course, the theory as such also mirrored a specific historical state of industrial society that only offered a limited scope of meaningful social roles and activities for older people (Estes, Binney, \& Culbertson, 1992). Nevertheless, more recent gerontological theorising points in a similar direction. Thus, in a refinement of his stage model of personal development, psychologist Erik Erikson explained that one crucial adaptive challenge in the trajectory to later life is marked by generativity, that is, an increasing awareness of one's role in a larger context, be it the overarching chain of generations or an all-encompassing cosmic order (Erikson \& Erikson, 1997). In a similar vein, the conception of gerotranscendence rehabilitates ideas of disengagement by emphasising the increasing relevance of self-decentralisation, integration into a larger whole and self-transcendence in old age, drawing attention to holistic dimensions of spirituality and historical as well as ecological awareness (Tornstam, 1989). Accordingly, current gerontological studies point out the important role of mindfulness, transcendence, and spirituality for older people's wellbeing and meaning in later life (Ardelt \& Ferrari, 2018; Bester, Naidoo, \& Botha, 2016; Thauvoye, Vanhooren, Vandenhoeck, \& Dezutter, 2018).

But even if we are to accept that activity as such has some value for a good life at old age, the crucial question is: what activity in particular? From a philosophical perspective, the kind of activity in question, its specific character, context, and outcomes, is decisive for its ethical evaluation. This is also relevant for active ageing, for example, in view of the 'productivistic' conception of activity involved in the debate. In her seminal work The Human Condition (1958/1998), philosopher Hannah Arendt distinguishes three paradigmatic kinds of human activity and ways of life: labour, work, and action. The concept of labour comprises instrumental activities to fulfil basic human needs, ensure survival, and afford procreation. Arendt emphasises that these activities traditionally belonged into the private sphere and were considered subaltern and even slavish because they merely served the necessities of biological self-preservation and reproduction and did not reflect the mastery of craftsmanship or the dignity of free citizenship (Arendt, 1958/1998, pp. 79-135). The category of work comprises skilful technical activities that achieve a specific result or product, e.g., the professional activities practised in various arts and crafts. According to Arendt, they transcend the private life and have a specific value since they cultivate the individual's skills and contribute to building an enduring common world (Arendt, 1958/1998, pp. 136-174). The concept of action finally refers to public activities and interactions as citizens of a political community. For Arendt, these are of supreme and intrinsic value since they alone allow and promote the public manifestation of the self as well as collective self-government (Arendt, 1958/1998, pp. 176-247). However, according to Arendt's perspective, modern life is essentially constituted by technological progress and industrialisation and therefore preoccupied with industrial labour and technological manufacturing while the classical republican ideal of (superior) political (inter-)action, self-manifestation, and collective self-government has been forgotten and needs to be recovered (Arendt, 1958/1998, pp. 248-326).

These philosophical distinctions show important connections to the social gerontological debates on active ageing. First, many gerontological approaches confirm the modern obsession with labour Arendt diagnoses. Early sociological theories of ageing in the context of structural functionalism particularly seem to mirror the value system and priorities of modern industrial society (Estes et al., 1992). Thus, regardless of their diametrically opposed orientations, both disengagement theory and activity theory focus on the trajectory from labour life into retirement as the crucial process defining the phase of old age and its characteristic opportunities and challenges. While the former spells out the implications of consequential retirement, the latter promotes the "busy ethics" (Ekerdt, 1986) of upholding previous activity levels (Katz, 2000). However, both theories lack a view on the meaning of ageing that transcends the institutionalised life course of modern industrial society and welfare state administration. Even accounts emphasising the relevance of non-labour activities such as crafts and civic 
engagement often seem to do so in terms of an instrumental usefulness for psychological adaptation or economic welfare (van Dyk, 2014). What is missing in this utilitarian perspective is the idea that these activities not only have a therapeutic or economic function, but also an inherent value for a good life at old age since they are constitutive of personal identity, meaningful practices, and human flourishing. Indeed, recent gerontological studies highlight the importance of manual leisure activities, volunteering, and political engagement for fulfilment and meaning in later life (Kenning, 2015; Kruse \& Schmitt, 2015; Morrow-Howell, Hinterlong, Rozario, \& Tang, 2003).

Furthermore, even if we were to accept the economic focus of active ageing on productivity, the philosophical distinctions introduced can help spell out the ethical problems of the underlying economic definition of productivity. Thus, for Arendt, the genuinely productive activity is work since it results in the production of durable artefacts and thus in the construction of a common world, a truly human institutional and cultural civilisation (Arendt, 1958/1998, pp. 136-139). By contrast, Arendt does not consider labour productive in this substantial sense since it is part of the process of mere biological self-preservation and satisfaction of needs and involves no real telos, no final aim and definite accomplishment. Occasionally, she even seems to join Camus in associating modern industrial labour with the futile and absurd activities Sisyphus and the other inhabitants of the mythological underworld are condemned to perform ad infinitum (Arendt, 1958/1998, pp. 96-101). From this perspective, many conceptions of active ageing not only suffer from a reduction of activity to productive activity, but also from a reduction of productivity to something ultimately unproductive and meaningless: man's participation in the endless metabolism of nature (Marx). This line of thought thus provides an important normative basis and differentiation for a gerontological critique of economic instrumentalism. To put it bluntly, what is problematic in this paradigm is that it ultimately levels the ethically crucial distinction between the necessities of mere survival and the intrinsic value of a good, desirable, and fulfilled life.

As we have seen, Hannah Arendt's philosophical typology and evaluation of different kinds of activities prove rather instructive for spelling out and substantiating prominent lines of critique of active ageing discourses and programs. In fact, with the appraisal of the concept of (political) action, her approach also already hints at a positive vision of activity in old age. At the same time, the distinction between labour, work, and action is located on a rather abstract and general theoretical level. A more differentiated account of the value of various human activities could provide even more concrete clues for gerontological debates on active ageing and especially for developing a more comprehensive positive conception of ageing well. Such an account has been developed by philosopher Martha C. Nussbaum in her capa- bility approach (Nussbaum, 2011). Similar to Arendt's reflections on the vita activa, the capability approach also starts from an ethical appreciation of human activities. According to Nussbaum (2011, p. 18), one of the central questions of any political ethics is: "What is each person able to do and to be?" Consequently, she defines a set of activities and aspects of life that constitute core elements of human wellbeing and flourishing so that any decent political community has to secure and promote them (Nussbaum, 2011, p. 18). Concretely, Nussbaum identifies a number of fundamental areas of human experience and corresponding fields of activities human beings must be able to perform in order to have the opportunity to live a good life.

The resulting list represents an open compilation of central capabilities that are necessary preconditions of human flourishing and a dignified existence (for the following, see Nussbaum, 2011, pp. 33-34). It first includes elementary needs and requirements like the ability to live to the end of a human life of normal length without dying prematurely (life), the ability to have good health, adequate nourishment and shelter (bodily health), and the ability to move freely from place to place, be secure against violent assault, and have reproductive autonomy (bodily integrity). Further basic capabilities refer to sensual, emotional, and intellectual dimensions of human existence, including the ability to make use of one's senses and to imagine, think, and reason in a truly human way (senses, imagination, and thought); the ability to develop attachments to things and other people and to experience love, grief, longing, gratitude, as well as justified anger (emotions); and the ability to form a conception of the good and to engage in critical deliberations about the planning of one's own life. Eventually, a third group of basic capabilities comprises abilities to take up relations and partake in interactions that are constitutive of a meaningful human life, especially being able to live with and towards others and to recognise and show concern for them (affiliation), to experience relations to animals, plants, and the world of nature as a whole (other species), or to enjoy playful and recreational activities (play), as well as the ability to participate in political decisions that are relevant for one's own life (control over one's environment).

Although this list represents a widely recognised set of criteria for the good life, it still remains to be specified in view of ageing (Ehni, Kadi, Schermer, \& Venkatapuram, 2018). Thus, not all capabilities are equally important for the discussion of old age. The criteria of life and bodily health appear too general to be informative in view of later life. It is not clear what exactly living through a normal lifespan and having good health mean in this context. Do healthcare measures that are considered life-sustaining or health-preserving in younger years also have to be provided for people at a very old age (Kaufman, 2015)? Furthermore, some of the aspects discussed seem to be targeted at middle adulthood. Thus, it is not clear whether reproduction should be consid- 
ered a part of a good life in later years and therefore be supported by social systems, e.g., by coverage of reproductive technologies (Rimon-Zarfaty \& Schweda, 2019). Nevertheless, other capabilities are obviously highly relevant for old age. This holds true for the aspect of bodily integrity including the ability to move freely, to be secure against violent assault, and to find sexual satisfaction, which are often compromised in the case of older people, especially those living in institutional settings like nursing homes (Tuominen, Leino-Kilpi, \& Suhonen, 2016). Moreover, the use of the senses, the imagination, and intellectual capacities may rather pertain to the theoretical or contemplative dimension of human existence neglected in the active ageing discourse; still, according to a capability approach, being able to use the imagination and thought, for example in connection with experiencing and producing works of art, must be considered a central dimension of good life at old age. Indeed, recent gerontological studies underline the potential of creative activities for wellbeing in later life (Creech, Hallam, Varvarigou, McQueen, \& Gaunt, 2013; Reynolds, 2010). The same holds true for capabilities related to emotions. Being able to have attachments to things and people, to love, grieve, experience longing, gratitude, and anger remains vital in later life. Gerontological research has long established that an emotionally rich and fulfilled life in relationships with others constitutes a central prerequisite for wellbeing at old age (Courtin \& Knapp, 2017).

By contrast, the ability to form a conception of the good and to engage in critical reflection about the planning of one's life (practical reason) has only recently been acknowledged as a concern of old age where traditionally defeatist and nihilistic views prevailed and positive ideals or meaningful role models for older people are still often missing (Moody, 1992; Riley, Kahn, Foner, Mack, 1994). Aspects of social affiliation and interaction are particularly important at old age, not only as a therapeutic or economic requirement but also as an integral element of a good human life of older people. Being able to experience other species and nature and to play are particularly interesting points since they represent activities that clearly point beyond the economistic and productivistic focus of active ageing but must still be considered essential parts of a good life at old age. Accordingly, current gerontological research identifies activities such as gardening or playing as important factors for wellbeing in later life (Gerling, De Schutter, Brown, \& Allaire, 2015; Scott, Masser, \& Pachana, 2015). The same holds true for the capability to participate in political choices that govern one's life. This perspective transcends economically exploitable civic engagement and instead requires possibilities for substantial political participation at old age, regardless of their contribution to an overall win-win-calculation. Recent gerontological work actually shows an increasing awareness of the interdependencies between wellbeing and political participation at old age (Barnes, Gahagan, \& Ward, 2018). Along these lines, a capability approach can contribute to a more comprehen- sive and ethically more articulate perspective on human flourishing at old age. It not only helps to detect biased and distorted conceptualisations of active ageing focusing on economic productivity and individual lifestyle, but also makes the idea of holistic self-development in old age more profound and differentiated.

\section{Conclusions}

Against the backdrop of previous deficit-oriented notions of ageing in terms of inevitable decline and disengagement, the active ageing discourse set out to promote a more positive vision of old age. However, the question of why exactly enduring activity should offer a promising and worthwhile perspective for later life remained largely undiscussed, let alone answered. The frequent references to health, social usefulness, and economic welfare are ultimately begging the question since it is not clear why and to what extent health, usefulness, and welfare themselves should be considered valuable. Hence, at the heart of the active ageing discourse, there is a largely unarticulated ideal of good life at old age.

This inarticulate ideal makes active ageing programs an easy target for criticism. Especially critical gerontologists object that these programs propagate biased models of ageing whose political implementation discriminates against and excludes whole groups of older people. However, unless the underlying eudemonistic question of the good life at old age is tackled, the whole debate takes place on shaky ground. The fact that the critics appeal to a different kind of moral philosophical standard, essentially comprising justice and equal rights, does not help to resolve the problem. After all, being excluded from a way of life that turns out to be ultimately worthless and undesirable would not necessarily constitute an injustice (maybe actually quite the opposite). Moreover, a system of moral norms and political regulations centred on a misguided ideal of human existence would ultimately impede each and everybody in the realisation of a good life.

As Walsh, Scharf and Keating (2016, p. 81) remind us, research in the field of social exclusion of old age is still under-developed. The existing empirical studies often concentrate on problems of labour market integration and consequently ignore multiple other forms of exclusion in different social spheres as well as the issue of their intersectional interaction. In this way, critical social research on old age exclusion runs the risk of reproducing the same shortcomings that are already inherent in the criticised conceptions of active ageing themselves. In addition, Walsh and colleagues deplore that the existing efforts and contributions to the debate usually remain trapped within the confines of their respective subdisciplines, thus not only losing useful empirical insights but also wasting potential for critical theory-building on social exclusion (Walsh et al., 2016, p. 82).

Our study underlines the potential of an interdisciplinary approach: an ethical analysis helps clarify evalu- 
ative and normative assumptions and thus strengthens the argumentative foundations of the discussion. It first makes clear that the preference for activity is far from self-evident and neglects other valuable dimensions of human life that may be more relevant and accessible to many older people, e.g., intellectual, aesthetic, or spiritual experience. Furthermore, the ethical distinction of different kinds of human activity helps explain what is wrong with specific understandings of active ageing, especially those promoted under the paradigm of economic instrumentalism. An understanding of activity in terms of economic productivity privileges an impoverished labour-oriented model of meaningful action and neglects other more productive and valuable kinds of activity contributing to a good life at old age, especially self-care work, arts and crafts, and political participation. Finally, a capability approach can provide a starting point for formulating a truly holistic conception of selfdevelopment and a comprehensive matrix of aspects and dimensions relevant for leading a good life at old age. With its wide and inclusive anthropological scope, it can help detect shortcomings of current ideals of ageing and justify the relevance of different aspects of good life at old age. Of course, further empirical research has to explore older adults' actual subjective assessment of the various dimensions of good life at old age as well as the role of further individual factors, such as resilience (e.g., Kok, Aartsen, Deeg, \& Huisman, 2015; Kok, van Nes, Deeg, Widdershoven, \& Huisman, 2018). This way, gerontological research could at the same time also contribute to an expansion and elaboration of the capability approach in view of old age.

As we have argued, the introduction of an ethical perspective can help to make clear what exactly is morally wrong with biased, one-sided ideals of ageing well: by neglecting and effectively blocking relevant dimensions of human value experience and self-fulfilment, they degrade, discriminate, and ultimately exclude certain ways of life and growing old from public recognition and political support. At the same time, the critical analysis also opens up constructive perspectives for a layered model of inclusive ageing policies. Thus, a capability approach helps define minimal preconditions and fundamental criteria that must be met in order to be able to live a decent human life at old age. In particular, precarious living situations and social inequalities threatening life, bodily integrity, and personal freedom at old age have to be denounced and fought throughout the life course. At the same time, however, an inclusive notion of the good life at old age also has to acknowledge the increasing plurality of individual lifestyles and living situations, especially in later life. Hence, beyond the fundamental level of basic needs and capabilities, ageing policies in modern liberal democracies are well advised to allow for a range of legitimate diversity and thus leave room for individual interpretations and prioritisations of different aspects of the good life such as aesthetic experience and production, creative activities and crafts, or active politi- cal engagement. Only this way can the abundance of possibilities to experience value in later life be fully explored and savoured.

\section{Acknowledgments}

This work was completed within the framework of the project "Successful = Healthy = Good Aging?" funded by the German Federal Ministry of Health (grant no. ZMV I 1-2516 FSB 017). We also would like to thank the editors and anonymous reviewers for their helpful comments.

\section{Conflict of Interests}

The authors declare no conflict of interests.

\section{References}

Ardelt, M., \& Ferrari, M. (2018). Effects of wisdom and religiosity on subjective well-being in old age and young adulthood: Exploring the pathways through mastery and purpose in life. International Psychogeriatrics, 31(4), 477-489.

Arendt, H. (1998). The human condition. Chicago, IL: University of Chicago Press. (Original work published 1958)

Barnes, M., Gahagan, B., \& Ward, L. (2018). Re-imagining old age: Wellbeing, care and participation. Wilmington, NC: Vernon Press.

Bester, E., Naidoo, P., \& Botha, A. (2016). The role of mindfulness in the relationship between life satisfaction and spiritual wellbeing amongst the elderly. Social Work, 52(2), 245-266.

Boas, T. C., \& Gans-Morse, J. (2009). Neoliberalism: From new liberal philosophy to anti-liberal slogan. Studies in Comparative International Development, 44(2), 137-161.

Bodhi, B. (2011). What does mindfulness really mean? A canonical perspective. Contemporary Buddhism, 12(1), 19-39.

Boudiny, K. (2013). 'Active ageing': From empty rhetoric to effective policy tool. Ageing \& Society, 33, 1077-1098.

Butler, D. C. (2001). Western mysticism. The teaching of Augustine, Gregory and Bernard on contemplation and the contemplative life (2nd ed.). Eugene, OR: Wipf \& Stock.

Cardona, B. (2008). 'Healthy ageing' policies and antiageing ideologies and practices: On the exercise of responsibility. Medicine, Health Care and Philosophy, 11(4), 475-483.

Cooper, J. M. (1987). Contemplation and happiness: A reconsideration. Synthese, 72(2), 187-216.

Courtin, E., \& Knapp, M. (2017). Social isolation, loneliness and health in old age: A scoping review. Health \& Social Care in the Community, 25(3), 799-812.

Creech, A., Hallam, S., Varvarigou, M., McQueen, H., \& Gaunt, H. (2013). Active music making: A route to 
enhanced subjective well-being among older people. Perspectives in Public Health, 133(1), 36-43.

Cumming, E., \& Henry, W. (1961). Growing old: The process of disengagement. New York, NY: Basic Books.

Ehni, H.-J., Kadi, S., Schermer, M., \& Venkatapuram, S. (2018). Toward a global geroethics: Gerontology and the theory of the good human life. Bioethics, 32, 261-268.

Ekerdt, D. J. (1986). The busy ethic: Moral continuity between work and retirement. Gerontologist, 26(3), 239-244.

Emirbayer, M., \& Mische, A. (1998). What is agency? American Journal of Sociology, 103(4), 962-1023.

Erikson, E. H., \& Erikson, J. M. (1997). The life cycle completed. Extended version with new chapters on the ninth stage of development. New York, NY: W. W. Norton \& Co.

Estes, C. L., Binney, E. A., \& Culbertson, R. A. (1992). The gerontological imagination: Social influences on the development of gerontology, 1945-present. International Journal of Aging and Human Development, 35(1), 49-65.

G7. (1996). Jobs ministerial conference in Lille, France, April 1-2. Conclusions of the chair. G8 Toronto. Retrieved from http://www.g8.utoronto.ca/ employment/labour1996.htm

G8. (1997). Communique: The Denver summit of the eight. US Department of State. Retrieved from https://1997-2001.state.gov/issues/economic/ summit/communique97.html

Gerling, K., De Schutter, B., Brown, J., \& Allaire, J. (2015). Ageing playfully: Advancing research on games for older adults beyond accessibility and health benefits. In Proceedings of the 2015 annual symposium on computer-human interaction in play (pp. 817-820). New York, NY: ACM.

Havighurst, R. (1961). Successful aging. Gerontologist, 1, 8-13.

Havighurst, R., \& Albrecht, R. (1953). Older people. New York, NY: Longmans, Green and Co.

Holstein, M. B., \& Minkler, M. (2003). Self, society, and the 'new gerontology'. Gerontologist, 43(6), 787-796.

International Council on Active Aging. (2018). Mission and vision. ICAA. Retrieved from https://www.icaa. cc/about_us/missionvision.htm

Katz, S. (1996). Disciplining old age. The formation of gerontological knowledge. Charlottesville, VA: University Press of Virginia.

Katz, S. (2000). Busy bodies: Activity, aging, and the management of everyday life. Journal of Aging Studies, 14(2), 135-152.

Katz, S. (2013). Active and successful aging. Lifestyle as a gerontological idea. Recherches Sociologiques et Anthropologiques, 44(1), 33-49.

Katz, S., \& Calasanti, T. (2015). Critical perspectives on successful aging: Does it "appeal more than it illuminates"? Gerontologist, 55(1), 26-33.
Kaufman, S. R. (2015). Ordinary medicine: Extraordinary treatments, longer lives, and where to draw the line. Durham, NC: Duke University Press.

Kenning, G. (2015). "Fiddling with threads": Craft-based textile activities and positive well-being. Textile, 13(1), 50-65.

Kok, A. A., Aartsen, M. J., Deeg, D. J., \& Huisman, M. (2015). Capturing the diversity of successful aging: An operational definition based on 16-year trajectories of functioning. Gerontologist, 57(2), 240-251.

Kok, A. A., van Nes, F., Deeg, D. J., Widdershoven, G., \& Huisman, M. (2018). "Tough times have become good times": Resilience in older adults with a low socioeconomic position. Gerontologist, 58(5), 843-852.

Kruse, A., \& Schmitt, E. (2015). Shared responsibility and civic engagement in very old age. Research in Human Development, 12(1/2), 133-148.

McKee, P., \& Barber, C. E. (2001). Plato's theory of aging. Journal of Aging and Identity, 6(2), 93-104.

Moody, H. R. (1992). The meaning of life in old age. In N. S. Jecker (Ed.), Aging and ethics (pp. 51-92). Totowa, NJ: Humana Press.

Morrow-Howell, N., Hinterlong, J., Rozario, P. A., \& Tang, F. (2003). Effects of volunteering on the well-being of older adults. The Journals of Gerontology Series B: Psychological Sciences and Social Sciences, 58(3), 137-145.

Moulaert, T., \& Biggs, S. (2013). International and European policy on work and retirement: Reinventing critical perspectives on active ageing and mature subjectivity. Human Relations, 66(1), 23-43.

Nussbaum, M. C. (2011). Creating capabilities: The human development approach. Cambridge, MA: The Belknap Press of Harvard University Press.

Ranzijn, R. (2010). Active ageing: Another way to oppress marginalized and disadvantaged elders? Aboriginal elders as a case study. Journal of Health Psychology, 15(5), 716-723.

Reynolds, F. (2010). 'Colour and communion': Exploring the influences of visual art-making as a leisure activity on older women's subjective well-being. Journal of Aging Studies, 24(2), 135-143.

Riley, M. W. E., Kahn, R. L., Foner, A. E., \& Mack, K. A. (1994). Age and structural lag: Society's failure to provide meaningful opportunities in work, family, and leisure. Oxford: John Wiley \& Sons.

Rimon-Zarfaty, N., \& Schweda, M. (2019). Biological clocks, biographical schedules and generational cycles: Temporality in the ethics of assisted reproduction. Bioethica Forum, 11(4), 133-141.

Robinson, D. N. (1990). Wisdom through the ages. In R. J. Sternberg (Ed.), Wisdom: Its nature, origins, and development (pp. 13-24). Cambridge: Cambridge University Press.

Rosenmayr, L. (1987). On freedom and aging: An interpretation. Journal of Aging Studies, 1(4), 299-316.

Rowe, J. W., \& Kahn, R. L. (1987). Human aging: Usual 
and successful. Science, 237(4811), 143-149.

Russell, D. C. (2010). Virtue ethics, happiness, and the good life. In D. C. Russell (Ed.), The Cambridge companion to virtue ethics (pp. 7-28). Cambridge: Cambridge University Press.

Scott, T. L., Masser, B. M., \& Pachana, N. A. (2015). Exploring the health and wellbeing benefits of gardening for older adults. Ageing \& Society, 35(10), 2176-2200.

Stückler, A. (2016). Schöne neue Alterswelt? Zum ideologischen Charakter des Active Ageing [Brave new world of ageing? The ideology in active ageing]. In C. von Stöckl, K. Kicker-Frisinghelli, \& S. Finker (Eds.), Die Gesellschaft des langen Lebens. Soziale und individuelle Herausforderungen [Long life society. Social and individual challenges] (pp. 29-44). Bielefeld: transcript.

Thauvoye, E., Vanhooren, S., Vandenhoeck, A., \& Dezutter, J. (2018). Spirituality and well-being in old age: Exploring the dimensions of spirituality in relation to late-life functioning. Journal of Religion and Health, 57(6), 2167-2181.

Timonen, V. (2016). Beyond successful and active ageing:
A theory of model ageing. Bristol: Policy Press.

Tornstam, L. (1989). Gero-transcendence: A reformulation of the disengagement theory. Aging Clinical and Experimental Research, 1(1), 55-63.

Tuominen, L., Leino-Kilpi, H., \& Suhonen, R. (2016). Older people's experiences of their free will in nursing homes. Nursing Ethics, 23(1), 22-35.

van Dyk, S. (2014). The appraisal of difference: Critical gerontology and the active-ageing paradigm. Journal of Aging Studies, 31, 93-103.

Walker, A. (2002). A strategy for active ageing. International Social Security Review, 55(1), 121-139.

Walsh, K., Scharf, T., \& Keating, N. (2016). Social exclusion of older persons: A scoping review and conceptual framework. European Journal of Ageing, 14(1), 81-98.

WHO. (2002). Active ageing. A policy framework. A contribution of the World Health Organization to the Second United Nations World Assembly on Ageing, Madrid, Spain, April 2002. WHO. Retrieved from https://www.who.int/ageing/publications/ active_ageing/en

\section{About the Authors}

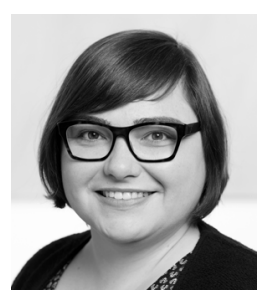

Larissa Pfaller (Dr) is Research Associate at the Institute of Sociology, Friedrich-Alexander University Erlangen-Nürnberg, Germany. Coming from cultural sociology, her research is based on qualitative social research. She is especially interested in the topics of ageing and end of life, as well as organ donation and the body, and wrote her PhD on the usage of anti-ageing medicine.

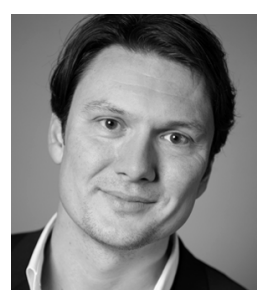

Mark Schweda (Dr) is Professor of Ethics in Medicine at the Department for Health Services Research, School of Medicine and Health Sciences, University of Oldenburg, Germany. His research focuses on philosophical and bioethical questions of ageing, the life course, and human temporality. Recent publications include Planning Later Life. Bioethics and Public Health in Aging Societies (Routledge, 2017, edited together with Larissa Pfaller, Kai Brauer, Frank Adloff and Silke Schicktanz). 